\title{
Oxygen-ozone therapy in dentistry: current applications and future prospects
}

\author{
Antonello Pulga \\ Dentistry Specialist, Asiago (VI); Italian Society for Oxygen-Ozone Therapy (SIOOT), Gorle (BG), Italy
}

\begin{abstract}
Starting from 2012, the dental research community began to assess the benefits of oxygen-ozone on human metabolism, for its immune-stimulant and anti-hypoxic action, the increase in protein biosynthesis and activation of angiogenesis.

We report the case of a 69 -year-old patient, for whom oxygenozone therapy was used as a treatment that could reduce the bone resorption of the alveolar ridges, considering the reduced state of hypoxia resulting therefrom, the improved neoangiogenesis and the positive effect on bone metabolism. The results exceeded our greatest expectations, given that the measurements even showed an increase in bone peaks.
\end{abstract}

\section{Introduction}

\section{History}

The earliest information about ozone dates back to 1785 , when Dutch scientist Van Marum noticed that the air near his electrostatic machine had acquired a characteristic odour.

In 1801, Cruickshank observed the same smell around the anode during the electrolysis of water. Later, in 1857, Werner Von Siemens designed an ozone generator which was used in the medical field, starting with the disinfection of operating theatres.

In 1902, Medical Reform - a scientific journal of the time reported positive observations on the use of ozone for treating tuberculosis and wound care.

\footnotetext{
Correspondence: Antonello Pulga, Italian Society for Oxygen-Ozone Therapy (SIOOT), Via Don Luigi Sturzo 2, 24020 Gorle (BG), Italy. E-mail: info@ossigenoozono.it
}

Key words: Dentistry; Teeth; Oxygen-ozone therapy.

Conflict of interest: the author declares no potential conflict of interest.

Received for publication: 3 December 2018

Accepted for publication: 5 December 2018.

(C) Copyright A. Pulga, 2018

Licensee PAGEPress, Italy

Ozone Therapy 2018; 3:7968

doi:10.4081/ozone. 2018.7968

This article is distributed under the terms of the Creative Commons Attribution Noncommercial License (by-nc 4.0) which permits any noncommercial use, distribution, and reproduction in any medium, provided the original author(s) and source are credited.
The Swiss dentist Dr. Edwin Parr began using ozone in 1920 as part of his disinfection system. ${ }^{1}$

In 1931, Dr. E.A. Fisch became a pioneer its odontoiatric application thanks to his use of ozonated water for dental procedures. $^{2}$

Despite the long history of oxygen-ozone therapy, even now, only $8 \%$ of doctors are familiar with its use. ${ }^{3}$ despite the impressive body of scientific research highlighting the positive biological effects in countless clinical applications.

In odontology, oxygen-ozone has long been used solely for its powerful antimicrobial effects, with the biological aspect of its use having only been taken into consideration more recently.

In an in vivo study of rabbits in 2011, El Hadary et al. observed that ozonated oil for topical use could influence both bone density and the quality of osseointegration around dental implants. ${ }^{4}$

However, it was not until 2012 that the dental research community began to assess the benefits of oxygen-ozone on human metabolism, for its immune-stimulant and anti-hypoxic action, the increase in protein biosynthesis and activation of angiogenesis. ${ }^{5}$

\section{Daily role of oxygen-ozone in dentistry}

- Hygiene

- Stomatitis and candida albicans ${ }^{6}$

- Aphthous stomatiti ${ }^{7}$

- Herpes ${ }^{8,9}$

- Dental restoration ${ }^{10,11}$

- Endodontics ${ }^{12,13}$

- Pre- and post-surgery

- Dental extractions

- Alveolar osteitis ${ }^{14}$

- Periodontology $5,15,16$

- Implantology: increase in implant hydrophilicity, ${ }^{17}$ treatment of peri-implantitis ${ }^{18,19}$

- ATM $^{20,21}$

- Bisphosphonate-associated osteonecrosis ${ }^{22,23}$

Nonetheless, many studies carried out in dentistry only consider oxygen-ozone for its antimicrobial effects, and only provide recommendations regarding application times, rarely reporting the concentrations used.

Yet, it is well known and has been confirmed by many experimental studies, that oxygen-ozone administration also has a therapeutic effect, amongst which is that it causes an increased release of interferons (IFN- $\alpha$, IFN- $\beta$, IFN $\gamma$ ), interleukins (IL- $1 \beta$, IL-2, IL6 , IL-8) and tumour necrosis factor (TNF- $\alpha$ ), in addition to the transformation of the growth factor (TGF- $\beta 1){ }^{24-28}$

Furthermore, ozone improves the rheological properties of erythrocytes and facilitates the release of oxygen into the tissue, ${ }^{29}$ which can be attributed to the stimulation of 2,3-diphosphoglycerate and the production of ATP in erythrocyte metabolism. ${ }^{30,31}$

Furthermore, it is possible to demonstrate that, during a Great Auto Emo Infusion (GAEI), a reduction in nitrosyl occurs in 
human endothelial cells, leading to vasodilation with an improvement in blood supply to the ischemic zones and hence a reduction of hypoxia. ${ }^{32}$ This phenomenon was confirmed by a reduction of vascular endothelial growth factor (VEGF) after the administration of oxygen-ozone. ${ }^{33}$ The synthesis of VEGF is induced in cells that are not receiving an adequate supply of oxygen. ${ }^{34}$ When a cell is in hypoxia, it produces Hypoxia Inducible Factor (HIF), a transcription factor that stimulates the release of VEGF which is able to induce the process of angiogenesis.

\section{Role of oxygen-ozone in bone regeneration}

In an animal study, oxygen-ozone was found to increasethe production of BMP-2 and osteocalcin, favouring the re-absorption of xenotransplants and improving bone regeneration, particularly in the early stages of healing. ${ }^{35}$

In another animal study, the application of oxygen-ozone therapy appeared to stimulate bone regeneration, with a concentration of $25 \mu \mathrm{g} / \mathrm{mL}$ proving to be the most effective dose. ${ }^{36}$

The origins of osseointegrations date back to the early 1950s, when Swedish professor Per-Ingvar Brånemark started to conduct experiments with titanium implant chambers to study blood flow into rabbit bones. He found that the bone integrated so intimately with the implant, it was impossible to remove the chamber. Brånemark called this discovery Osseointegration, and proposed a protocol for surgical implants ${ }^{37}$ that involved using titanium screws in edentulous patients in order to stabilise the prostheses. The reduced availability of residual bone tissue in the edentulous ridges limited the suitability of such implants to the anterior area of the mandible only.

Subsequently, a new scientific concept emerged, in which, it was argued, that the early insertion of implants, following a dental extraction, could somehow slow down the physiological process of bone resorption by the alveolar ridges, which would therefore make it possible to successfully insert the implants within other areas of the mouth as well. This therapeutic concept was introduced in $1976^{38}$ as an alternative protocol to the classic delayedimplant surgical protocol proposed by Brånemark. Proponents of this therapeutic concept also affirmed that the reduced exposure of patients to surgery could limit physiological bone resorption, with improved aesthetic outcomes. ${ }^{39,40}$

However, the results did not support the expectations; there was always an immediate reabsorption of the vestibular cortex, leading to exposure of the initial coils of the implant even after two months. ${ }^{41-43}$

This process was analysed in a series of experimental studies published by researchers at the University of Gothenburg, clearly demonstrating that reabsorption in the alveolar ridge occurs independently of the timing of implant insertion and, in fact, significant changes are observed in the buccal bone wall, both in the apicocoronal and buccolingual positions, in the 4-12 weeks following the post-extraction implant placement. ${ }^{44,45}$

This histologic result was further corroborated by human clinical studies, which demonstrated a reduction of up to $56 \%$ in the bucco-lingual position of the alveolar ridge size around implants with immediate positioning. ${ }^{46}$

In addition to these preliminary investigations, many studies have been published throughout the last twenty years demonstrating that implant survival rates, the degree of osseointegration and the maintenance of inter-dental bone levels are not negatively influenced by the immediate implant placement protocol, even if only a few studies have reported results about peri-implant health, soft tissue and aesthetic results. ${ }^{47,48}$ Nonetheless, the data on the quantity and relevance of bone resorption occurring in the vestibular bone conflicts with experimental and clinical studies. ${ }^{49}$
In clinical practice, the implant is positioned $2 \mathrm{~mm}$ below the level of the crestal bone to compensate for the relative bone loss, ${ }^{50}$ which sometimes results in a less favourable aesthetic outcome.

From an anatomical perspective, the alveolar bone surrounding the tooth at the coronal level is represented by a small and thin band of bone tissue, with a micro vascular component, drawing nourishment from the periosteum and the periodontal ligament.

Bone resorption would be caused due to the surgical stress resulting from the extraction, with the response seeming closely correlated to angiogenesis and haemodynamics.

Micro vascular responses following muco-periosteal flap surgery and periodontal ligament responses may cause circulatory impairment via the Volkmann's canals in the vascular plexus of the periosteum and the periodontal ligament itself, thus leading to a state of hypoxia. The bone resorption that occurs on the surface of the alveolar bone and in the alveolar bone itself is due to the process established to restore the circulatory processes. ${ }^{51,52}$

\section{Case Report}

A patient, aged 69 years, ASA1, smoker (8-15 cigarettes per day), with old crowns and bridges, who was unable to carry out the correct hygiene procedures at home, came under our observation. There were multiple destructive infiltrations beneath the coronals, which had led to severely compromised teeth 16-15-25. The chief complaint was that I absolutely do not want to have bridges, in that the patient requested a prosthetic solution that would allow proper hygiene procedures, without using Superfloss thread beneath the prosthetic framework, this being a manoeuvre they found rather difficult, due to the presence of a tight oral junction.

The treatment plan proposed therefore provided for the extraction of severely compromised teeth and their replacement by implant therapy.

In May 2016, tooth number 25 was extracted using a conservative method and an alloplastic filler of bovine origin for conservation of the alveolus (Cerabone Granulate 1.0-2.0 mm, Botiss Dental), all being covered by a membrane with non-transfusional blood components (Concentrated Growth Factor - CGF - obtained using the Silfradent method).

While waiting for surgery, the patient came across some brochures about oxygen-ozone therapy produced by the Italian Society for Oxygen-Ozone Therapy (SIOOT) in our waiting room. Following a request for information, the patient was offered a treatment plan for subsequent extractions, in accordance with the patient's personal commitments, that foresaw the administration of oxygen-ozone outlined in Table 1.

The patient accepted the proposed treatment plan, and signed the informed consent form.

In November 2016, a pre-extraction Cone Beam Computed Tomography scan (Scanora, Soredex) was performed, which allowed us to correctly assess the clinical situation, schedule the operation and complete radiologic measurement of the positions of the coronal margins of the alveolar ridge of teeth 16 and 15 (Figure 1). Using DICOM-specific image processing software (OnDemand3 $\mathrm{D}^{\mathrm{TM}}$ by Cybermed Inc.), we created a virtual straight line, linking the tips of tooth 17 and 14 . This line was used as the point of reference for subsequent measurements.

We then proceeded with the extraction of teeth 16 and 15 using a conservative method and an alloplastic filler of bovine origin for alveolus conservation (Cerabone Granulate 1.0-2.0mm, Botiss Dental), everything being covered by a membrane with non-trans- 

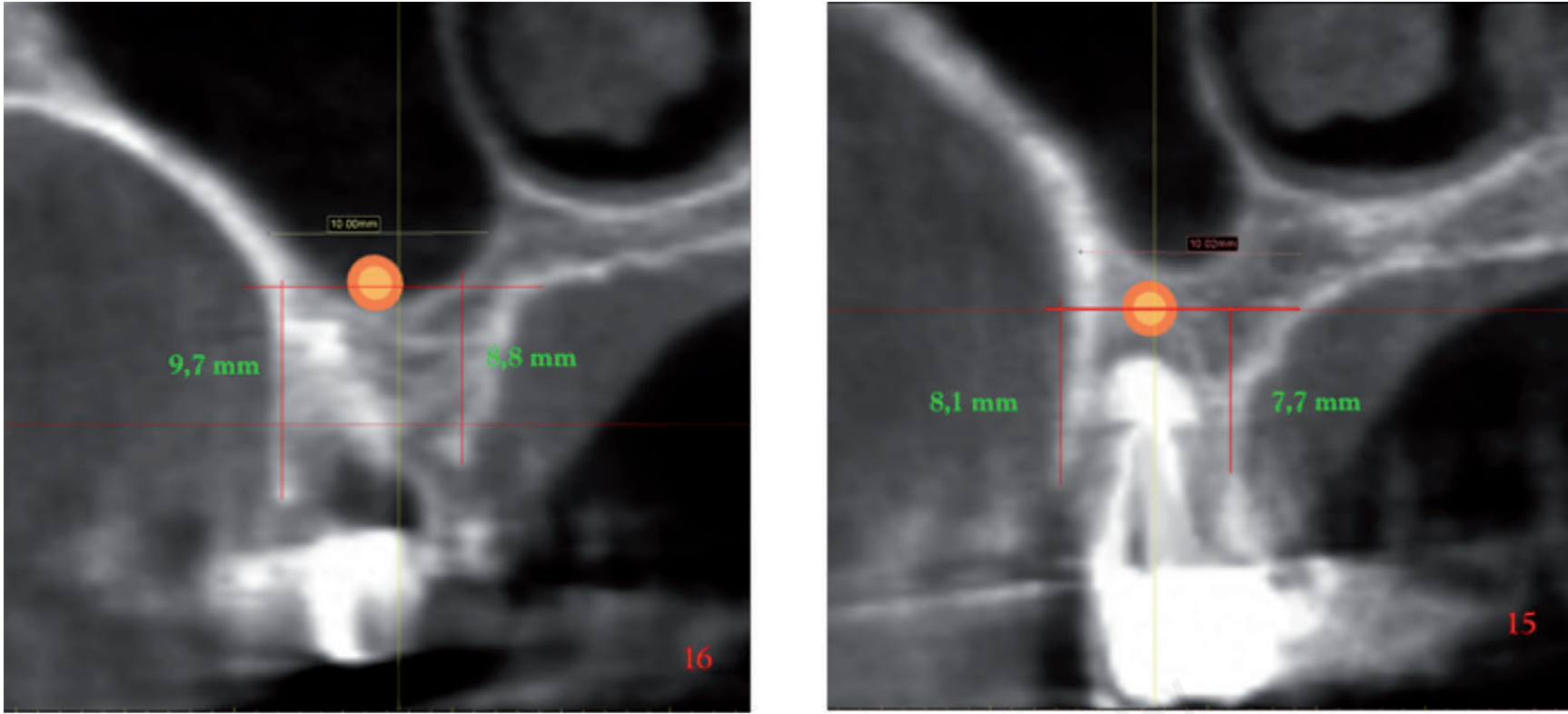

Figure 1. Pre-extraction Cone Beam computed tomography scan of the alveolar ridge of teeth 16 and 15.

fusional blood components (CGF obtained using the Silfradent method) (Figure 2).

A Type-2 implant insertion (delayed) was scheduled for enhanced soft tissue control. ${ }^{53}$

Thus, 8 weeks after the extractions, on February 2017 to be precise, we repeated the CBTC for new assessments and measurements of osseous availability, again using DICOM-specific image processing software (OnDemand3 $\mathrm{D}^{\mathrm{TM}}$ by Cybermed Inc.). We recreated the virtual straight line connecting the tips of teeth 17 and 14 for comparison measurements.

The post-extraction measurements we performed confirmed an increase in the coronal tips of the alveolar bone respectively at + $0.77 \mathrm{~mm}$ buccally and $+0.06 \mathrm{~mm}$ palatally for tooth number 16 ; and $+3 \mathrm{~mm}$ buccally and $+1.6 \mathrm{~mm}$ palatally for tooth number 15 (Figure 3).

At an initial objective examination, comparing the mucosal profiles that remained from the extraction of teeth 16 and 15 (performed with the support of oxygen-ozone) with the residual profile of 25 (without oxygen-ozone support), we could already predict a

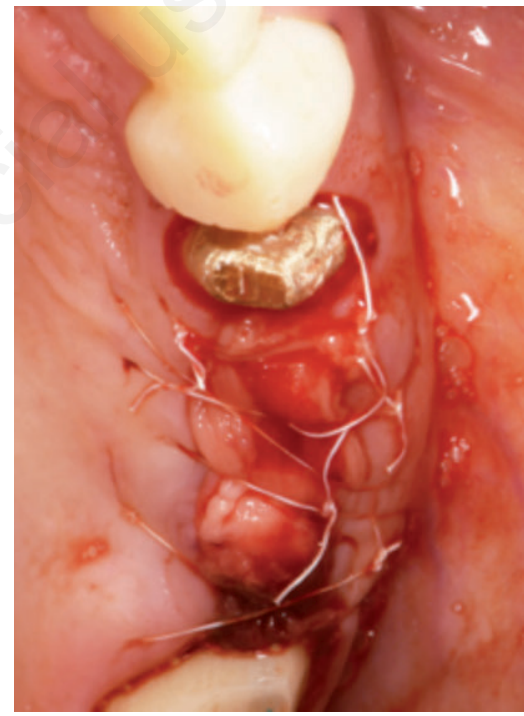

Figure 2. Extraction of teeth 16 and 15 using a conservative method and an alloplastic filler of bovine origin for alveolus conservation (Cerabone Granulate 1.0-2.0mm, Botiss Dental), covered by a membrane with nontransfusional blood components.

Table 1. Oxygen-ozone administration.

\begin{tabular}{llll}
\hline First week & Tuesday & GAEI & $200 c c \times 30 \mathrm{y}$ \\
& Friday & GAEI & $200 \mathrm{cc} \times 30 \mathrm{y}$ \\
Second week & Tuesday & $16-15$ extractions & - \\
& Friday & GAEI & $200 \mathrm{cc} \times 30 \mathrm{y}$ \\
\hline \multirow{2}{*}{ Third week } & Tuesday & Submucosal insufflation & $2 \mathrm{cc} \times 15 \mathrm{y}$ \\
& Friday & GAEI & $200 \mathrm{cc} \times 30 \mathrm{y}$ \\
Forth week & Tuesday & Submucosal insufflation & $2 \mathrm{cc} \times 18 \mathrm{y}$ \\
& Friday & GAEI & $200 \mathrm{cc} \times 30 \mathrm{y}$ \\
\hline Fifth week & Tuesday & Submucosal insufflation & $2 \mathrm{cc} \times 20 \mathrm{y}$ \\
& Friday & GAEI & $200 \mathrm{cc} \times 30 \mathrm{y}$ \\
Sixth week & Tuesday & Submucosal insufflation & $2 \mathrm{cc} \times 25 \mathrm{y}$ \\
& Friday & GAEI & $200 \mathrm{cc} \times 30 \mathrm{y}$ \\
\hline
\end{tabular}

GAEI, great auto emo infusion. 

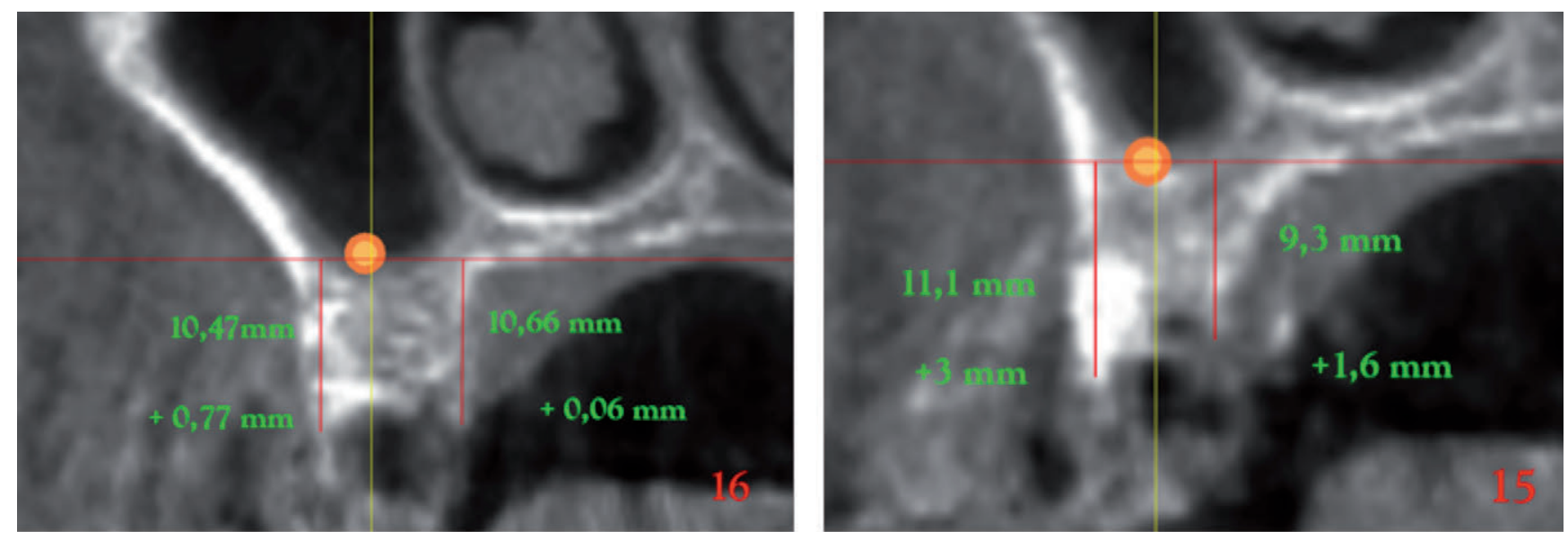

Figure 3. The post-extraction measurements confirmed an increase in the coronal tips of the alveolar bone.

greater conservation of bone peaks for the bone crests at 16 and 15 (Figure 4).

The intraoperative implantology phase confirmed greater conservation of the bone peaks, as expected following the objective examination (Figure 5).

Once implanted, it was possible to note a difference in bone levels, which were close to zero for implants 16 and 15, whilst implants 25 and 26 had to be placed in a more apical position, given the greater resorption of the bone crest (Figure 6).

\section{Discussion}

As noted, the bone surrounding the teeth is a functional type of tissue, in that it exists as long as it is stressed by the load of the dental element. At present, scientific literature is in agreement with the estimation that, following dental extraction, bone resorption always occurs, regardless of the technique used. Even the postextraction insertion of an implant, whether immediate or delayed, cannot prevent such a phenomenon, being greater when it comes to the buccal bone peaks that are anatomically thinner and frailer.

Between 2003 and 2005, Nobuto et al. ${ }^{51,52}$ demonstrated that
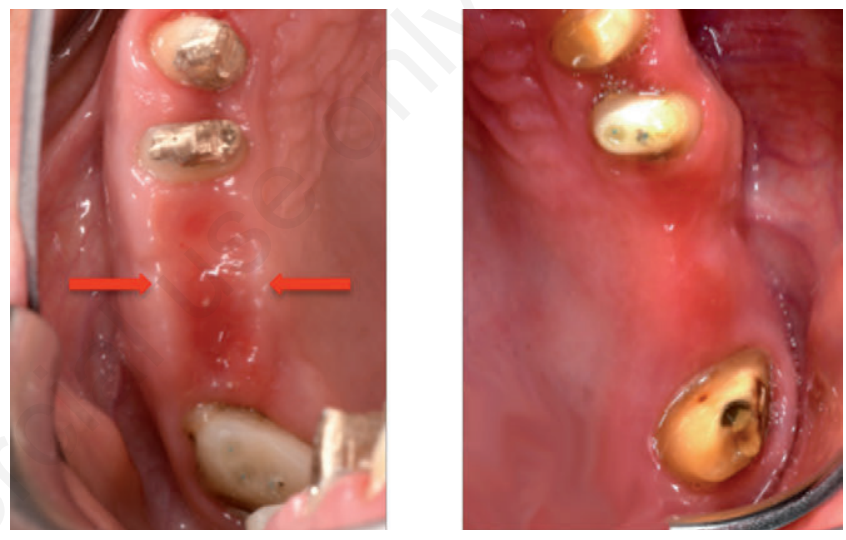

Figure 4. Greater conservation of bone peaks for the bone crests at 16 and 15.

the vascular component of the alveolar bone peaks consists of a dense network of micro blood vessels that draw directly from the periodontal ligament and the periosteum. The authors have stated
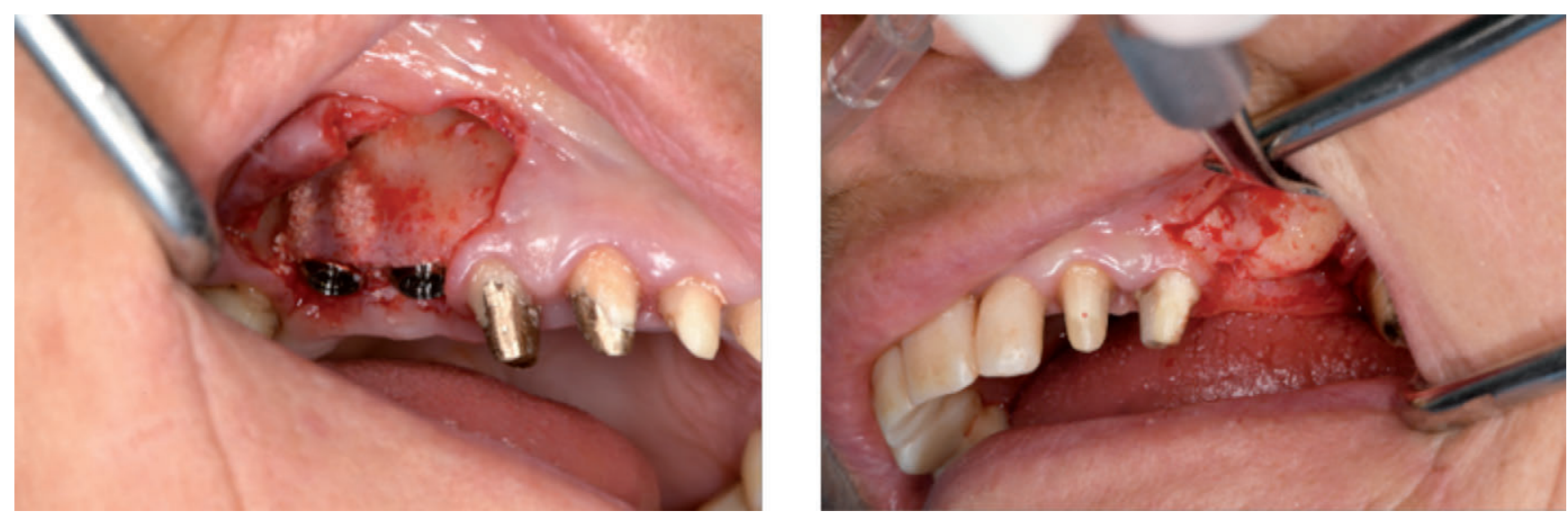

Figure 5. The intraoperative implantology phase confirmed greater conservation of the bone peaks, as expected following the objective examination. 

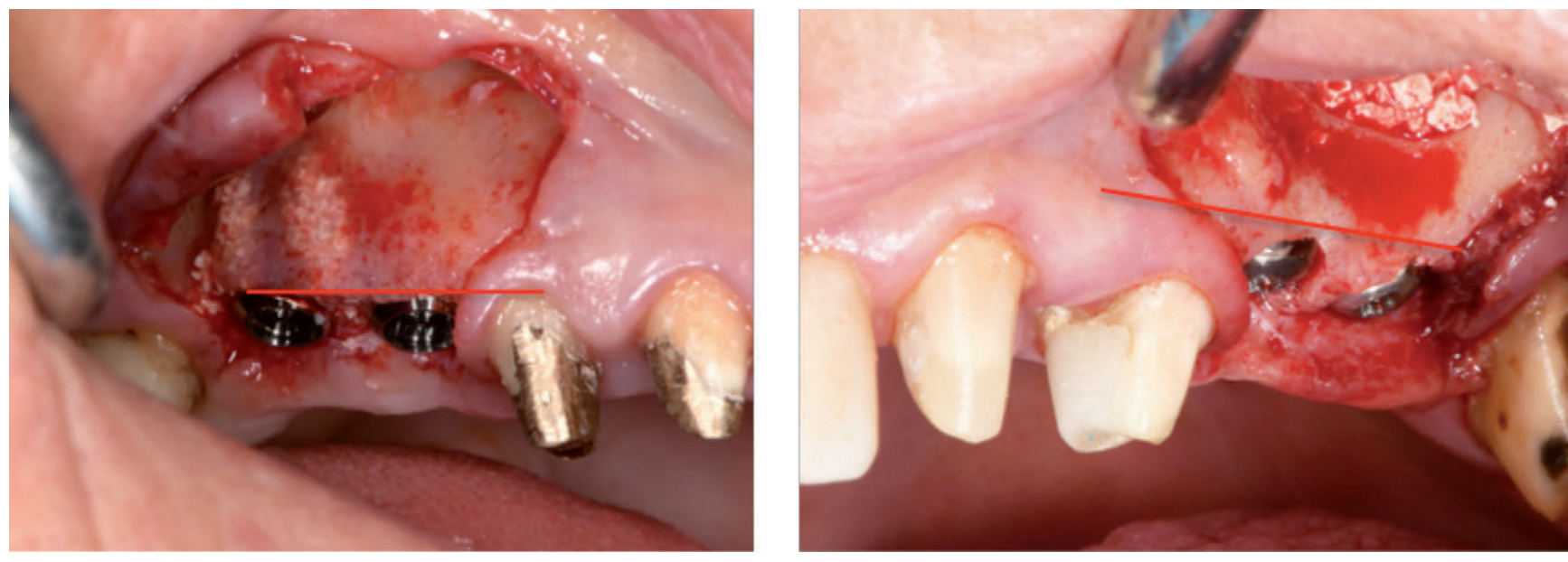

Figure 6. Once implanted, we noted a difference in bone levels, which were close to zero for implants 16 and 15, whilst implants 25 and 26 had to be placed in a more apical position, given the greater resorption of the bone crest.

that the reabsorption could be due to the state of hypoxia created in these micro vessels as a consequence of the body's attempt to restore a new vascularisation, following the surgical impact deriving from dental extraction.

This was the rationale that motivated us to use oxygen-ozone as a therapy that could reduce the bone resorption of the alveolar ridges, considering the reduced state of hypoxia resulting therefrom, the improved neoangiogenesis and the positive effect on bone metabolism. In fact, the results exceeded our greatest expectations, given that the measurements even showed an increase in bone peaks.

\section{Conclusions}

Despite a single case report being of no value from a statistical perspective, our clinical impression is that the use of oxygen-ozone support therapy can create advantages and benefits, not only in maintaining the alveolus post-extraction, but in all regenerative surgical procedures. However, further studies will be needed to validate our results and give statistical significance to the procedure we have adopted.

\section{References}

1. Giunta R, Coppola A, Luongo C, et al. Ozonized autohemotransfusion improves hemorheological parameters and oxygen delivery to tissuesin patients with peripheral occlusive arterial disease. Ann Hematol 2001;80:745-8.

2. Sameer M, Monica M. Ozone treating dental infections. Ind J Stomatol 2011;2:256-9.

3. Donati F. New method for oxygen-ozone therapy in bladder and vaginal infections: Preliminary results. Int J Ozone Ther 2013;12:74-82.

4. El Hadary AA, Yassin HH, Mekhemer ST, et al. Evaluation of the effect of ozonated plant oils on the quality of osseointegration of dental implants under the influence of Cyclosporin A an in vivo study. J Oral Implantol 2011;37:247-57.
5. Gupta G, Mansi B. Ozone therapy in periodontics. J Med Life 2012;5:59-67.

6. Noites R, Pina-Vaz C, Rocha R, et al. Synergistic Antimicrobial action of chlorhexidine and ozone in endodontic treatment. Biomed Res Int 2014;2014:592423.

7. Logan R. The use of topical ozone to treat recurrent aphthous ulceration. Dental Asia 2005;48-51.

8. Shenberg J, Blum C. Gaseous and aqueous ozone therapy for treatment of mucositis secondary to chemotherapy/radiotherapy: a case report. Pain Practition 2011;21:68-73.

9. Jordan L, Beaver K, Foy S. Ozone treatment for radiotherapy skin reactions: is there an evidence base for practice? Eur J Oncol Nurs 2002;6:220-7.

10. Unal M, Oztas N. Remineralization capacity of three fissure sealants with and without gaseous ozone on non-cavitated incipient pit and fissure caries. J Clin Pediatr Dent 2015;39:364-70.

11. Didem A, Nurhan O. Effectiveness of ozone with or without the additional use of remineralizing solution on non-cavitated fissure carious lesions in permanent molars. Eur J Dent 2011;5:393-9.

12. Case PD, Bird PS, Kahler WA, et al. Treatment of root canal biofilms of Enterococcus faecalis with ozone gas and passive ultrasound activation. J Endod 2012;38:523-6.

13. Hems RS, Gulabivala $\mathrm{K}, \mathrm{Ng}$ YL, et al. An in vitro evaluation of the ability of ozone to kill a strain of Enterococcus faecalis. Int Endod J 2005;38:22-9.

14. Kotze M, Bütow KW, Olorunju SA, Kotze HF. Ozone treatment of alveolar bone in the cape chacma baboon does not enhance healing following trauma. J Maxillofac Oral Surg 2014;13:140-7.

15. Srikanth A, Sathish M, Sri Harsha AV. Application of ozone in the treatment of periodontal disease. J Pharm Bioallied Sci 2013; 5:S89-S94.

16. Martinez-Abreu J, Weisser MT, Menendez-Cerero S. Therapeutic effects of Ozone therapy in adult periodontitis treatment, subtypes I and II. J Ozone Ther 2015;1.

17. Sunarso, Toita R, Tsuru K, Ishikawa K. A superhydrophilic titanium implant functionalized by ozone gas modulates bone marrow cell and macrophage responses. J Mater Sci Mater Med 2016;27:127. 
18. Hauser-Gerspach I, Vadaszan J, Deronjic I, et al. Influence of gaseous ozone in peri-implantitis: bactericidal efficacy and cellular response. An in vitro study using titanium and zirconia. Clin Oral Investig 2012;16:1049-59.

19. McKenna DF, Borzabadi-Farahani A, Lynch E. The effect of subgingival ozone and/or hydrogen peroxide on the development of peri-implant mucositis: a double-blind randomized controlled trial. Int J Oral Maxillofac Implants 2013;28:1483-9.

20. Daif ET. Role of intra-articular ozone gas injection in the management of internal derangement of the temporomandibular joint. Oral Surg Oral Med Oral Pathol Oral Radiol 2012;113:e10-4.

21. Doğan M, Ozdemir Doğan D, Düger C, et al. Effects of highfrequency bio-oxidative ozone therapy in temporomandibular disorder-related pain. Med Princ Pract 2014;23:507-10.

22. Kaptan F, Kazandag MK, Iseri U. Treatment of bisphosphonate related osteonecrosis following root canal therapy at the 1-year follow-up: report of two cases. Ther Clin Risk Manag 2013;9:477-82.

23. Stübinger S, Sader R, Filippi A. The use of ozone in dentistry and maxillofacial surgery: a review. Quintessence Int 2006;37:353-9.

24. Bocci V, Paulescu L. Studies on the biological effects of ozone: 1. Induction of interferon on human leukocytes. Haematologica 1990;75:510-5.

25. Bocci V, Luzzi E, Corradeschi F, Silvestri S. Studies on the biological effects of ozone: 6. Production of transforming growth factor 1 by human blood after ozone treatment. J Biol Regul Homeost Agents 1994;8:108-12.

26. Bocci V, Luzzi E, Corradeschi F, et al. Studies on the biological effects of ozone: 4. Cytokine production and glutathione levels in human erythrocytes. J Biol Regul Homeost Agents 1993; 7:133-8.

27. Bocci V, Valacchi G, Corradeschi F, Fanetti G. Studies on the biological effects of ozone: 8 . Effects on the total antioxidant status and on interleukin- 8 production. Mediators Inflamm 1998;7:313-7.

28. Bocci V, Luzzi E, Corradeschi F, et al. Studies on the biological effects of ozone: 3. An attempt to define conditions for optimal induction of cytokines. ymphokine Cytokine Res 1993;12:121-6.

29. Verrazzo G, Coppola L, Luongo C, et al. Hyperbaric oxygen, oxygen-ozone therapy, and rheologic parameters of blood in patients with peripheral occlusive arterial disease. Undersea Hyperb Med 1995;22:17-22.

30. Bocci V. Ozone as a bioregulator. Pharmacology and toxicology of ozone therapy today. J Biol Regul Homeost Agents 1996;10:31-53.

31. Viebahn-Hänsler R. Allgemeine Eigenschaften des Ozons. In: Beck EG, Viebahn-Hänsler R, eds. Ozon-Handbuch: Grundlagen-Prävention-Therapie. Landsberg: EcoMed; 1995.

32. Valacchi G, Bocci V. Studies on the biological effects of ozone: 11. Release of factors from human endothelial cells. Mediators Inflamm 2000;9:271-6.

33. Xie TY, Yan W, Lou J, Chen XY. Effect of ozone on vascular endothelial growth factor (VEGF) and related inflammatory cytokines in rats with diabetic retinopathy. Genet Mol Res 2016;15.

34. Holmes K, Roberts OL, Thomas AM, Cross MJ. Vascular endothelial growth factor receptor-2: structure, function, intra- cellular signalling and therapeutic inhibition. Cell Signal 2007;19:2003-12.

35. Alpan AL, Toker H, Ozer H. Ozone therapy enhances osseous healing in rats with diabetes with calvarial defects: a morphometric and immunohistochemical study. J Periodontol 2016;87:982-9.

36. Buyuk SK, Ramoglu SI, Sonmez MF. The effect of different concentrations of topical ozone administration on bone formation in orthopedically expanded suture in rats. Eur J Orthod 2016;38:281-5

37. Branemark PI. Osseointegration and its experimental background. J Prosthet Dent 1983;50:399-410.

38. Schulte W, Heimke G. The Tubinger immediate implant. Quintessenz 1976:27:17-23.

39. Lazzara RJ. Immediate implant placement into extraction sites: surgical and restorative advantages. Int $\mathrm{J}$ Periodontics Restorative Dent 1989;9:332-43.

40. Paolantonio M, Dolci M, Scarano A, et al. Immediate implantation in fresh extraction sockets. A controlled clinical and histological study in man. J Periodontol 2001;72:1560-71.

41. Araújo MG, Lindhe J. Dimensional ridge alterations following tooth extraction. An experimental study in the dog. J Clin Periodontol 2005;32:212-8.

42. Cardaropoli G, Araújo M, Lindhe J. Dynamics of bone tissue formation in tooth extraction sites. An experimental study in dogs. J Clin Periodontol 2003;30:809-18.

43. Discepoli N, Vignoletti F, Laino L, et al. Early healing of the alveolar process after tooth extraction: an experimental study in the beagle dog. J Clin Periodontol 2013;40:638-44.

44. Araujo MG, Lindhe J. Ridge alterations following tooth extraction with and without flap elevation: an experimental study in the dog. Clin Oral Implants Res 2009;20:545-9.

45. Araujo MG, Sukekava F, Wennstrom JL, Lindhe J. Tissue modeling following implant placement in fresh extraction sockets. Clin Oral Implants Res 2006;17:615-24.

46. Botticelli D, Berglundh T, Lindhe J. Hard-tissue alterations following immediate implant placement in extraction sites. J Clin Periodontol 2004;31:820-8.

47. Chen ST, Darby IB, Reynolds EC, Clement JG. Immediate implant placement postextraction without flap elevation. J Periodontol 2009;80:163-72.

48. Quirynen M, Van Assche N, Botticelli D, Berglundh T. How does the timing of implant placement to extraction affect outcome? Int J Oral Maxillofac Implants 2007;22:203-23.

49. Vignoletti F, Sanz M. Immediate implants at fresh extraction sockets: from myth to reality. Periodontol 2000 2014;66:132-52.

50. Elif Ö. Comparision success rate of immediate implants at fresh extraction sockets and conventional implants. Int J Oral Dent Health 2016;2:28.

51. Nobuto T, Suwa F, Kono T, et al. Microvascular response in the periosteum following mucoperiosteal flap surgery in dogs: angiogenesis and bone resorption and formation. J Periodontol 2005;76:1346-53.

52. Nobuto T, Imai H, Suwa F, et al. Microvascular response in the periodontal ligament following mucoperiosteal flap surgery. J Periodontol 2003;74:521-8.

53. Chen ST, Wilson TG Jr, Hämmerle CH. Immediate or early placement of implants following tooth extraction: review of biologic basis, clinical procedures, and outcomes. Int J Oral Maxillofac Implants 2004;19S:12-25. 